\title{
Postoperative Right Ventricular Failure in Cardiac Surgery
}

\author{
Victor H. Nieto Estrada ${ }^{a}$, , Daniel L. Molano Franco ${ }^{a}$, Albert A. Valencia Moreno ${ }^{a}$, \\ Jose A. Rojas Gambasica ${ }^{\text {a }}$ Cristian C. Cortes Nunez
}

\begin{abstract}
Two cases of patients that developed right ventricular failure (RVF) after cardiac valve surgery are presented with a narrative revision of the literature. RVF involves a great challenge due to the severity of this condition; it has a low incidence among non-congenital cardiac surgery patients, is more likely associated with cardiovascular and pulmonary complications related to cardiopulmonary bypass (CPB), and is a cause of acute graft failure and of a higher early mortality in cardiac transplant. The morphologic and hemodynamic characteristics of the right ventricle and some specific factors that breed pulmonary hypertension after cardiac surgery are in favor of the onset of RVF. Due to the possibility of complications after cardiac valve repair or replacement, measures as appropriate hemodynamic monitoring, to manage oxygenation, ventilation, sedation, acid base equilibrium and perfusion goals are a requirement, as well as a normal circulating volume, and the prevention of a disproportionate rise in the afterload, to preserve the free wall of the right ventricle (RV) and the septum's contribution to the right ventricular global function and geometry. If there is no response to these basic measures, the use of advanced therapy with inotropics, intravenous or inhaled pulmonary vasodilation agents is recommended; the use of mechanical ventricular assistance stands as a last resource.
\end{abstract}

Keywords: Right cardiac failure; Postoperative cardiac surgery; Physiopathology; Prevention and treatment

\section{Introduction}

Severe right ventricular failure (RVF) has a low incidence among non-congenital cardiac surgery patients $[1,2]$. When RVF takes place, it represents a significant clinical challenge at cardiovascular intensive care unit settings because of the high prevalence of morbidity and mortality [3]. There is little literature available on RVF in the context of cardiac surgery; pul-

Manuscript accepted for publication September 28, 2016

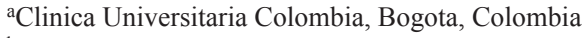

${ }^{\mathrm{b} C o r r e s p o n d i n g ~ A u t h o r: ~ V i c t o r ~ H u g o ~ N i e t o ~ E s t r a d a, ~ C l i n i c a ~ U n i v e r s i t a r i a ~ C o-~}$ lombia, Bogota, Colombia. Email: victor.nietoestrada@gmail.com

doi: https://doi.org/10.14740/cr500e monary hypertension $(\mathrm{PH})$ on the other hand is a well-studied phenomenon, but it is possible that the mortality associated with PH may be due to poor adaptation of the right ventricle to the pulmonary vasculature [4]. RVF is a serious complication that may occur whether the surgery is done on the left or right cardiac cavities [5].

The definition of right ventricular dysfunction after cardiac surgery varies from author to author, although it is always related to unfavorable outcomes. In a retrospective series of patients with ischemic cardiomyopathy that underwent coronary revascularization, a right ventricle fractional area change (RVFAC) of less than $35 \%$ was associated to longer days at intensive care units, more days of mechanical ventilation and a reduced hospital survival rate [6]. Pinzani et al found that in mitral or mitral-aortic repair or replacement, RVF, defined by clinical criteria, was a strong predictor of mortality, and only $28 \%$ of patients survived after 75 months of follow-up [2]. Denaut et al, in a series of 800 patients that underwent a cardiopulmonary bypass, found that the dynamic obstruction of the outflow tract in the right ventricle (RV) was associated with higher hemodynamic instability and difficulty in the disconnection from cardiopulmonary bypass (CPB) [1]. Hosenpud et al, while analyzing patients that underwent a heart transplant, reported that $20 \%$ of all early deaths were due to RVF [7].

Several factors may rouse an acute RVF after cardiac surgery. A multivariable logistic regression analysis of congenital cardiac disease surgery in adults showed that the preoperative dysfunction of the RV, supraventricular tachycardia, and a CPB time $>150$ min were the related determinants for RVF [5].

Cardiac transplant and left ventricular mechanical assistance are relevant clinical scenarios where RVF may be common. RVF after the implantation of a left ventricular assistance device (LVAD) occurs in around $11 \%$ of cases and has a high mortality rate [8]. Ochiai et al described that the need for inotropic support, female gender and non-ischemic etiology are variables associated with the need for right ventricle assistance device (RVAD) in patients with LVAD [9], Kormos et al emphasized that clinical factors such as fever, pulmonary edema and transfusions during surgery predict the need for right mechanical support better than the measurement of the right ventricular function before implantation [10].

In patients with cardiac transplant, the dysfunction of the $\mathrm{RV}$ is considered as an almost always-present syndrome, and RVF is one of the causes of this acute and severe dysfunction of the graft with clinical outcomes that are discouraging [11]. In a publication on the perioperative perspective of the RV in 


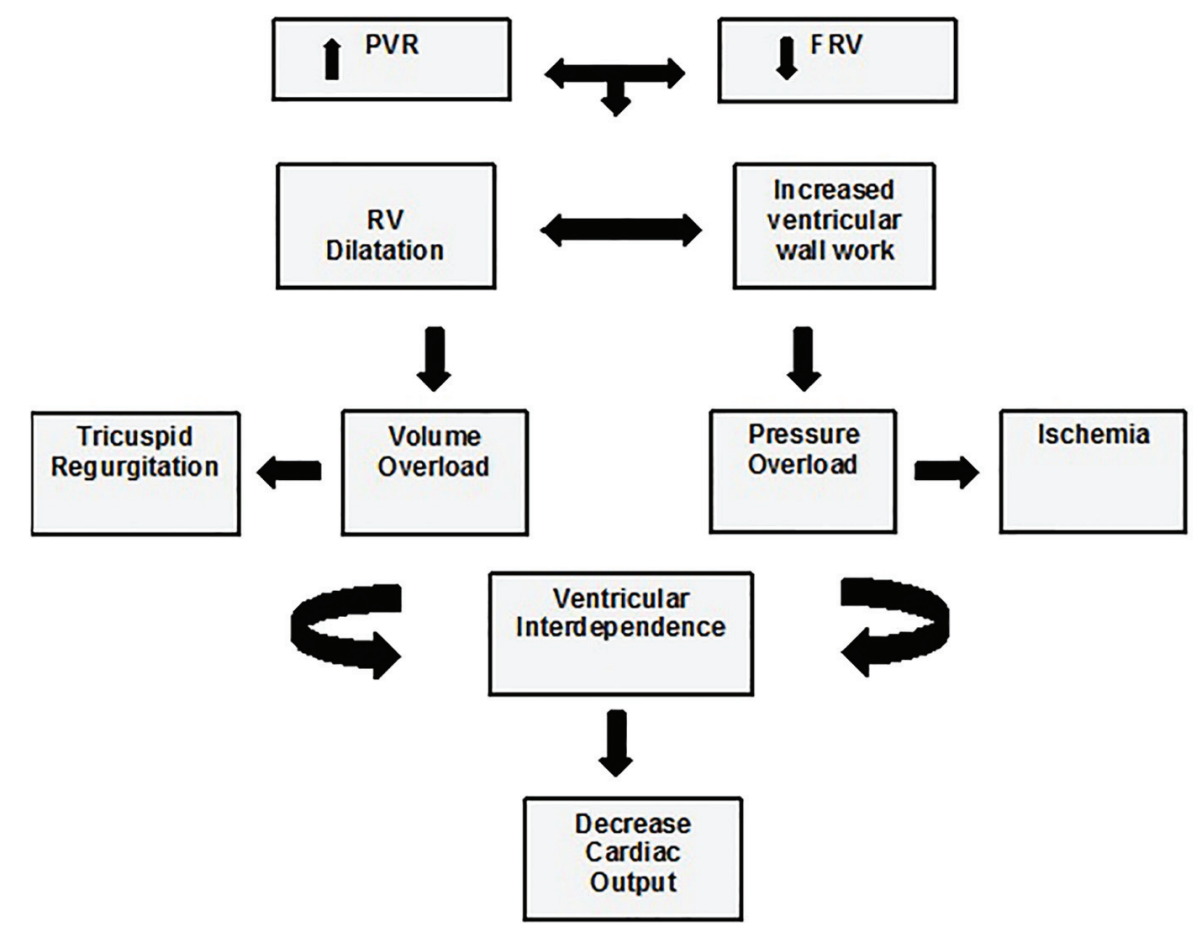

Figure 1. Physiopathology of right ventricular failure. FRV: function right ventricle; PVR: pulmonary vascular resistance. Taken and adapted from [16].

cardiac surgery, the author states that a vascular pulmonary resistance prior to the transplant $\geq 6$ Woods Units and a mean transpulmonary gradient $(\mathrm{TPG})>15 \mathrm{~mm} \mathrm{Hg}$ are associated with a higher incidence of RVF and perioperative mortality [12].

The conceptual variability and the poor clinical outcomes turn RVF in postoperative cardiac surgery to a partially resolved clinical problem. This publication presents two clinical cases and an updated clinical narrative revision based on the systematic strategy of medical literature research.

\section{Case analysis 1}

A 53-year-old male patient with a history of mitral valve replacement by a mechanical prosthesis due to infectious endocarditis visited his physician due to cardiac failure and fever symptoms, blood culture isolated Escherichia coli. Patient developed cardiogenic shock and required orotracheal intubation. The trans esophageal echocardiogram showed a paraprosthetic leak, dilation of the right cavities, tricuspid insufficiency and severe PH (PSAP $109 \mathrm{~mm} \mathrm{Hg}$ ) with preserved systolic biventricular function. On the fourth day of antibiotic treatment, there was a replacement of the mitral prosthesis and an annuloplasty of the tricuspid valve. The immediate postoperative period showed a suprasystemic rise in the arterial pulmonary pressure refractory to inodilators such as milrinone and levosimendan. Inhaled nitric oxide (INO) was administered with a transitory decrease in pulmonary pressure. The echocardiography control showed a higher growth of the right cavities with severe compromise of the contractibility of the RV. Treatment with digoxin and sildenafil was initiated without clinical response. The patient developed a multi-organic failure after which he died.

\section{Case analysis 2}

The patient was a 72-year-old male with a diagnosis of severe mitral valve insufficiency and moderate tricuspid insufficiency with a history of hypertensive cardiopathy, cor pulmonale and severe $\mathrm{PH}$. He was scheduled for mitral valve replacement, tricuspid plasty and Maze surgery. After the anesthetic induction, the pulmonary pressures increased dramatically with hemodynamic instability and only the mitral valve replacement could be accomplished. The aortic clamp time was $47 \mathrm{~min}$ and the time of extracorporeal circulation was $69 \mathrm{~min}$. To remove the pump, vasoactive and mechanical assistance with an intra-aortic balloon pump was necessary. The $\mathrm{PH}$ turned suprasystemic, required INO, inodilators, and sildenafil to achieve control of the $\mathrm{PH}$ and to be able to remove mechanical ventilation. After removing mechanical ventilation, the patient started a new pulmonary hypertension crisis requiring mechanical ventilation and pulmonary vasodilation therapy; the echocardiography control showed a detriment to the systolic function of the RV with severe dilation. At fifth day of treatment, the patient experienced significant signs of improvement, the removal of advanced support was achieved again after 15 days under clinical care and the patient left the hospital alive. 


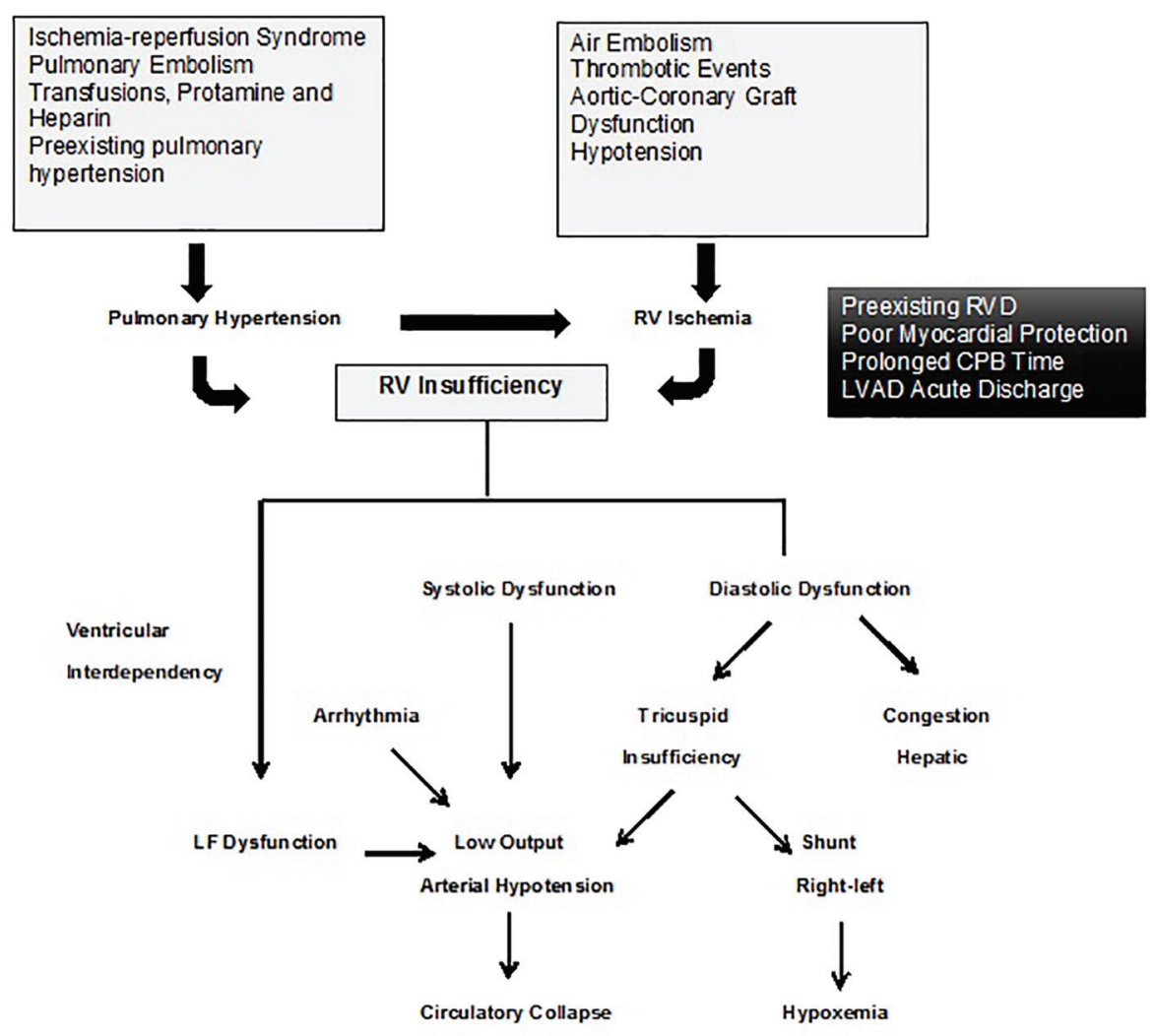

Figure 2. Physiopathology of the right ventricle after surgery. Taken and adapted from [17].

\section{Physiopathology of Right Cardiac Failure: Tra- ditional Approach}

The physiopathology of right cardiac failure traditionally has had a hemodynamic focus based on the characteristics of the $\mathrm{RV}$, regardless of the triggering factor.

The RV obeys the Frank-Starling law; compared to the left ventricle (LV), it has a thin wall with high distensibility and drains to an arterial system of low pressure and less resistance [13]; with any abnormality in the preload, afterload or contractibility, a rapid dysfunction of the RV is produced $[13,14]$. A noticeable increase of the preload enlarges the free wall, changing the morphology of the RV and displacing the interventricular septum, the contracting capacity is affected and due to the ventricular interdependency, it decreases the LV distensibility $[14,15]$.

The impedance of the pulmonary valve, the pulmonary vascular resistance, and the function of the left heart determine the afterload of the RV. Chronic increase of the afterload allows for compensatory changes to take place, nonetheless an acute increase is not well tolerated $[14,15]$; sudden elevation of pulmonary vascular resistance (PVR) leads to a rapid dilatation of the RV with an increase in the cardiac workload and contractile dysfunction $[14,15]$.

RVF decreases cardiac output, starting a vicious cycle where low cardiac output decreases coronary perfusion and RV function [16] (Fig. 1).

\section{Physiopathological Model of Acute Right Ven- tricular Insufficiency in Cardiac Surgery}

The specific physiopathology process of RVF after cardiac surgery is more complex than the traditional model. Several mechanisms have been attributed to RVF development, but according to the patient's conditions, more than one mechanism may concur; among these mechanisms, $\mathrm{PH}$ primarily associated with $\mathrm{CPB}$, preexisting $\mathrm{PH}$, and ventricular interdependency are between the most relevant, above all the latter [17] (Fig. 2).

Pulmonary vasoconstriction and acute increase in pulmonary resistance after removing the $\mathrm{CPB}$ may be due to inflammatory mediators that cause endothelial damage or due to ischemic and reperfusion mechanisms owing to inadequate blood flow through the bronchial arteries [17]. There is a lack of equilibrium between the vasodilation and vasoconstrictor substances with a reduction of nitric oxide and prostacyclin and an increase of the thromboxane A2 and endothelin [18]. There are specific factors related to cardiac surgery that may cause $\mathrm{PH}$ and disturb the hemodynamic determinants of the $\mathrm{RV}$, for example, administration of heparin and/or protamine, pulmonary microembolism phenomena, ischemia of the RV, metabolic acidosis, hypercapnia, hypothermia, hydric overload, poor myocardial protection, extended extracorporeal circulation (ECC) time, obstruction of vascular grafts, and loss of auricular-ventricular synchrony [13] (Fig. 3). 

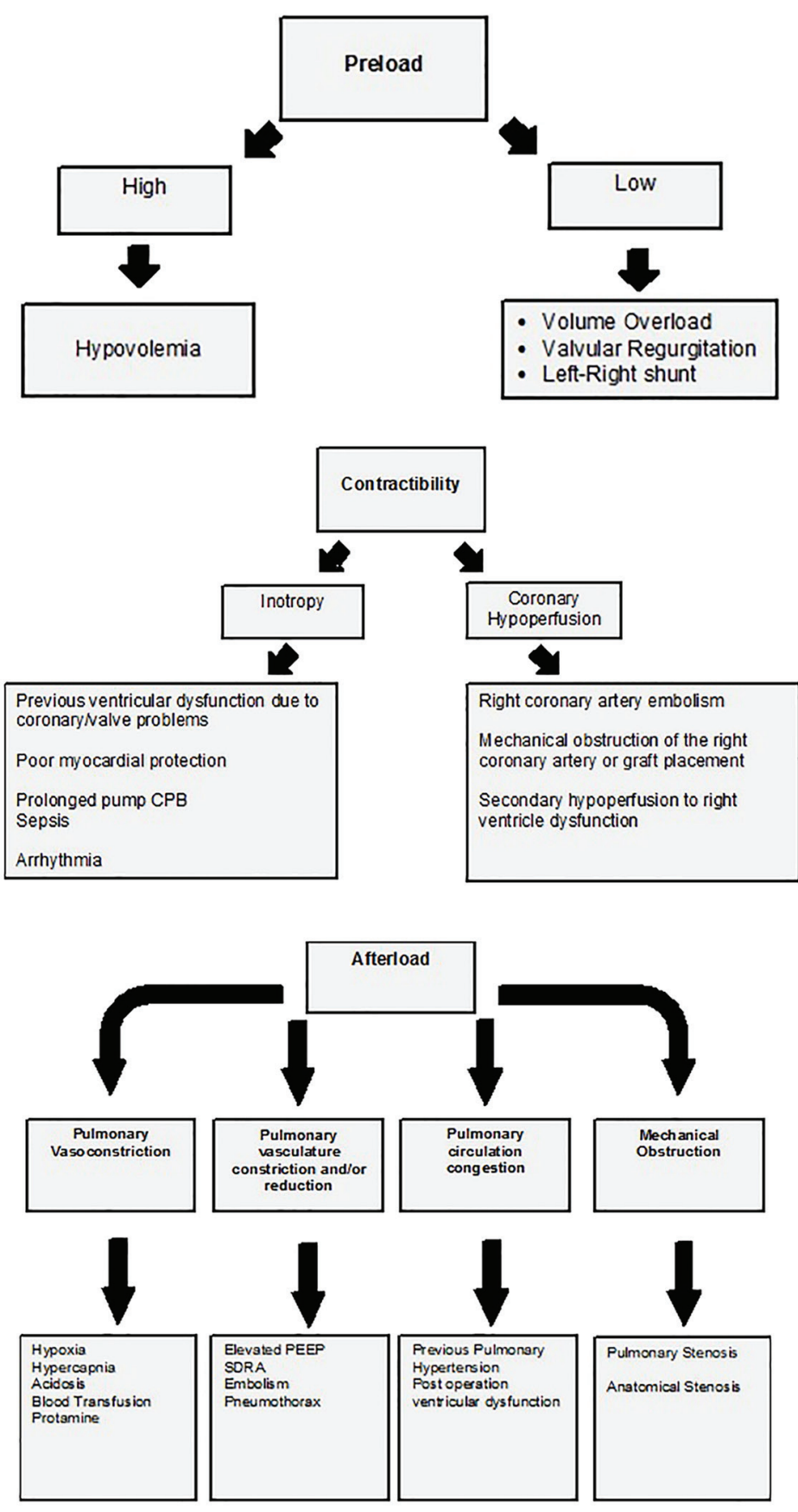

Figure 3. Features based in the Frank-Starling law related with acute right ventricular failure at post-cardiac surgery. Figure taken and adapted from [13].

Surgery without ECC in myocardial revascularization has been suggested as a protection factor of the right ventricular function, but a clinical trial with 50 patients failed to show the benefits on the right ventricular global function in a period of 3 months [19]. The administration of protamine may generate $\mathrm{PH}$, the severity of the clinical status is not related to the dosage, and three reactions have been described: transitory systematic hypotension, anaphylactoid reaction, and severe PH with circulatory shock with low incidence of catastrophic cases $(1.8 \%)$ [17]. Prostacyclin has been used with satisfactory outcomes, for the treatment of patients with RVF and protamine facilitated $\mathrm{PH}[20]$.

Acute PH and RVF due to ischemia and myocardial depression after $\mathrm{CPB}$ are temporary and generally do not cause a hemodynamic collapse, except in patients with previous $\mathrm{PH}$ [17]. Some causes of PH in cardiac surgery are: dysfunction of the LV, mitral valve disease [21], and the mismatch between the prosthetic and the patient; particularly this last one has 


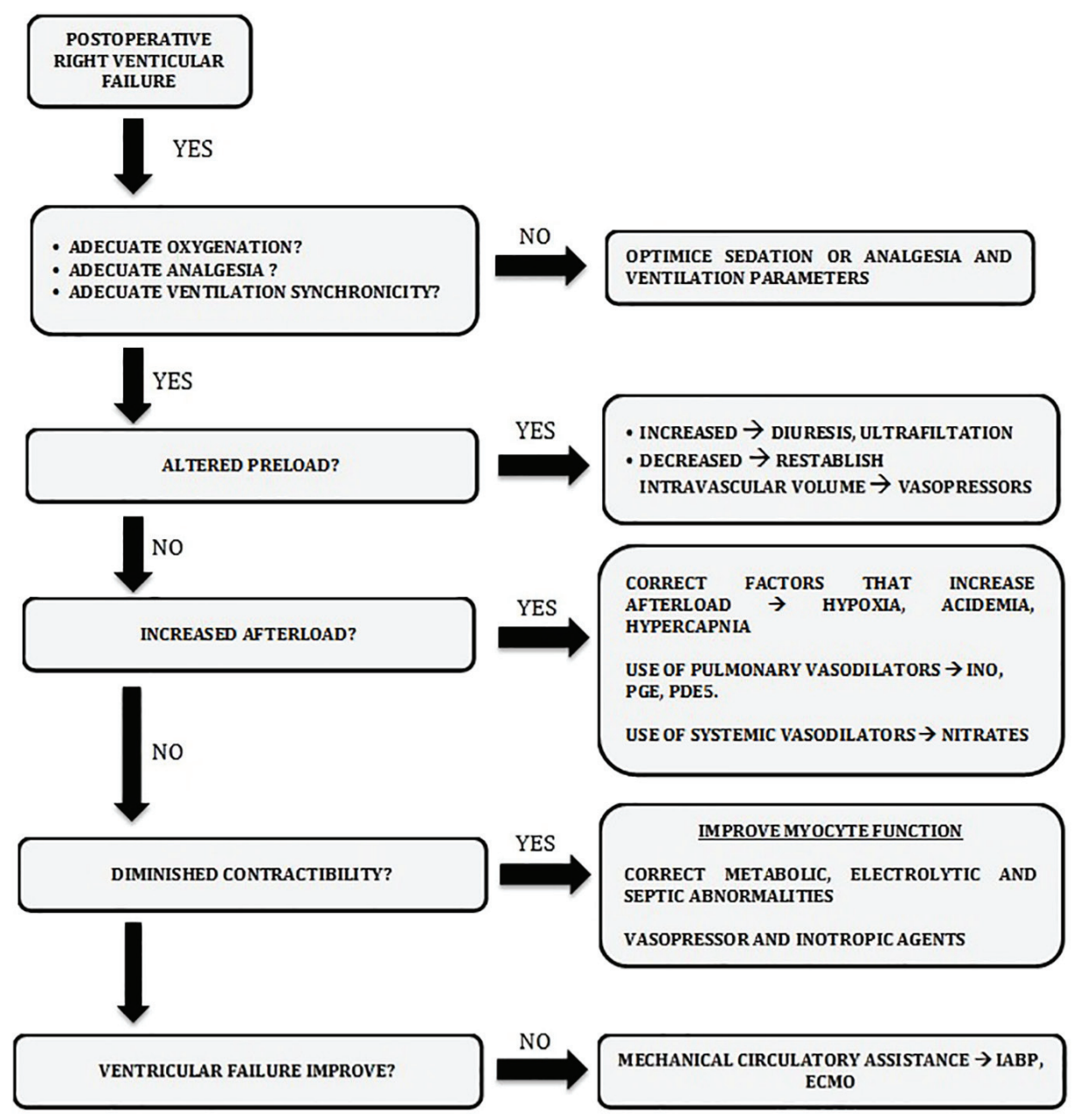

Figure 4. Management algorithm proposed in patients with postoperative right ventricular dysfunction.

been associated with a higher postoperative mortality rate [22]. In patients subjected to pulmonary thromboendarerectomy, age and the perioperative deterioration of the preexisting $\mathrm{PH}$ are known factors that impact hospital mortality [23].

Studies suggest that functional state of the interventricular septum is the most important determinant of the maximum right ventricular function [24]. During non-appropriate elevation of the afterload, almost half of the global function of the RV depends on the interventricular septum [17]. Contraction force of the LV is the primary determinant of the septum contribution to the global function of the RV, even more so than coronary perfusion [24]. Therefore, when the RV function is lost, recovering and maintaining the contribution of the interventricular septum could be important [25].

Ventricular interdependency has a determinant etiological role in LAVD-related RFV, due to the acute displacement of the septum that produces the emptying of the LF with mechanical assistance [17]. The loss of the septum contribution to the contraction of the RV modifies the contractility and the geometry of the RV, produces tricuspid regurgitation and may cause acute dysfunction [17]. These patients may benefit from a preoperative optimization of the RV function or even planned biventricular assistance [26].

\section{Diagnosis}

RVF after cardiac surgery may be defined as a clinical syndrome unleashed by the inability of the RV to supply blood to pulmonary circulation after the removal of the CPB or after cardiac surgery [17]. Three specific clinical scenarios have been described: 1) RVF associated with cardiotomy [17], distinguished by hemodynamic instability, difficulty of $\mathrm{CPB}$ removal and a long mechanical support requirement, with an incidence varying from $0.04 \%$ to $0.1 \%$ with mortality rates as high as $75 \%$ [22]; 2) low cardiac output syndrome due to biventricular insufficiency predominantly on right side (LCOS) [17], is a more frequent clinical scenario with a reported incidence from $3 \%$ to $45 \%$, characterized by signs of low cost, rarely presented due to isolated RVF, and for the majority of times, it is associated with LV dysfunction and a high mortality [3]; and 3) lastly, a lesser degree of RV dysfunction, which lacks clinical repercussion and does not lead to RVF, and is present in almost all patients subjected to CPB [17]. 
Monitoring and diagnosis strategies for the objective evaluation of the RV have limitations in critical patients, but pulmonary artery catheter and echocardiogram continue to be the strategies with the highest benefits [13]. Echocardiography is the less invasive method available, and allows physicians to estimate the function and the size of the RV since it is very difficult to measure the ejection fraction of the RV, and global function contractibility indexes of the RV. The most used methods are tricuspid annulus plane systolic excursion (TAPSE), Tei index or global myocardial behavior index, maximum speed of the tricuspid ring during systole through tissue Doppler, subjective evaluation of the RV dilation, and the fraction change as an equivalent parameter of the ejection fraction [17]. The American Society of Echocardiography recommends the routine use of at least one of the specific echocardiographic parameters to evaluate the RV function [27]. TAPSE method reflects the displacement of the tricuspid ring towards the apex as a measure of the longitudinal shortening of the RV; it is a simple and robust measure that may be performed and correlates well with the right ventricular ejection fraction estimated by a pulmonary arterial catheter [28].

The pulmonary arterial catheter provides relevant information with respect to hemodynamic parameters, even though it might be questioned in some scenarios. In the specific scenario of cardiothoracic surgery, its use overpowers the risks [17]. The isolated RVF diagnosis is recognized hemodynamically by elevated pressure in the right auricle (PRA), with a normal or low wedge pressure that indicates poor filling of the left auricle [17].

The final diagnosis is an addition of all the criteria [12]: 1) clinical criteria: difficulty in the removal of the CPB or LOCS after surgery that is not explained by the LV function or hypovolemia; 2) hemodynamic criteria: $\mathrm{PAD} \geq 18 \mathrm{~mm} \mathrm{Hg}$ or PAD/ wedge pressure ratio $\geq 1$, cardiac index $(\mathrm{CI}) \leq 2 \mathrm{~L} / \mathrm{min} / \mathrm{m}^{2}$, and medium arterial pressure $<60 \mathrm{~mm} \mathrm{Hg}$; and 3) echocardiographic criteria: dilation of the RV ( $>2 / 3$ of the LV in its transversal diameter); shortening fraction $<25 \%$ or a $20 \%$ reduction with respect to the pre-CPB evaluation; TAPSE $\leq 16$ $\mathrm{mm}$ and systolic speed of the Doppler tricuspid tissue ring < $10 \mathrm{~cm} / \mathrm{s}$ [12].

\section{Treatment}

Principles of RVF treatment after cardiac surgery are based on concepts of hemodynamic pathology. In case of any degree of right ventricular dysfunction, a number of basic interventions must be performed. Appropriate intravascular volume ensures an optimal preload; being able to attain good levels of oxygenation, maintain the acid-base equilibrium, and the synchronicity of the ventilator, avoiding a pleural overcharge and bronchospasm prevents sudden rises in the post-charge of the RV $[15,16]$; ensuring an adequate myocardial protection, maintaining perfusion of the tissue, and avoiding metabolic acidosis prevent the deterioration of the contractibility in the RV. If despite attaining these conditions, a typical case of RVF is established, it is necessary to do an advanced intervention, which may be pharmacologic, inotropics, or intravenous/ inhaled vasodilators, even using mechanical ventricular assistance (Fig. 4).

\section{Optimization of volume status}

The RV is highly dependent on volume, but hypovolemia as well as hypervolemia may compromise cardiac output and the perfusion of other organs. Hypovolemia is common in the first hours after surgery for two reasons: bleeding and increments in vascular permeability $[16,29]$ and hypervolemia is more frequent in the following days due to excessive reanimation with fluids. Volume administration must be guided with clear perfusion goals and predictors of fluid responsiveness, even though there is no consensus on which to use facing the variability of the performance with regard to static and dynamic response to volume in cardiac surgery studies. In a prospective study of pediatric patients, the variability of systolic volume (VSV) did not predict the volume response in cardiac surgery [30]. In a sub-analysis of a clinical trial focused on volume expansion, it was shown that a rise in basal $\mathrm{SVO}_{2}$ might be used as a predictor of fluid responsiveness with an area under the curve of 0.73 particularly in those patients with systolic dysfunction (global ejection fraction $(\mathrm{GEF}) \leq 20 \%)[31]$.

Lee and collaborators in a prospective study with 35 patients concluded that the pulse pressure variability (PPV) predicts the fluid responsiveness in surgery without ECC and may be used to guide fluid therapy [32]. A more recent publication from Fischer and collaborators found that the PPV and the VSV measured through non-invasive plethysmography do not forecast fluid responsiveness [33]. The use of automatic transesophageal echocardiography has shown that the breathing variation in the left ventricular systolic area (DeltaSA) may predict fluid responsiveness [34]. Belloni's work showed high sensibility in dynamic parameters regarding fluid responsiveness (PPV and VSV) regarding central venous pressure and wedge pressure. He found that, surprisingly, there was no correlation between the aortic peak flow change measured by echocardiography and the response status [35].

Hypervolemia is harmful to the RV, and an exaggerated increase in telediastolic volume may displace the interventricular septum; for this reason, it is important to identify and treat hypervolemia quickly with diuretics or hemofiltration [36].

\section{Afterload reduction with pulmonary vasodilators}

In this section, we will name the agents that have shown greater effect with respect to the treatment of postoperative RVF. Agents such as tezosentan have shown a positive effect in the management of PH of another etiology, but in cardiac surgery, it has not been proven to prevent endothelial dysfunction induced by CPB [37].

\section{INO}

This is a powerful selective pulmonary vasodilator, has rapid 
action and a short half-life, and is inactivated by hemoglobin in the lung capillaries which prevents systemic vasodilation; higher than $10 \mathrm{ppm}$ doses are not associated with a higher reduction of pulmonary vascular tone [38].

Some hemodynamic benefits have been described in postsurgical patients with mitral stenosis and severe $\mathrm{PH}$; it increases cardiac output and reduces pulmonary vascular resistance [39]. This medication has synergetic effect with inhaled iloprost in the reduction of pulmonary pressure and improves RV function [40]. Matamis and collaborators proved that the combined use with phosphodiesterase 5 (PDE5) inhibitors such as sildenafil has an additive effect in disproportionate PH control in cardiac surgery patients [41]. The PH rebound effect when treatment is interrupted quickly becomes a frequent complication; for this reason, treatment suspension must be monitored with precaution [42]. Chances of this secondary effect may also decrease when combined with sildenafil [43].

\section{Prostaglandins}

The E1 prostaglandin, epoprostenol (synthetic prostacyclin (PGI2)) and prostacyclin analogs such as iloprost are potent pulmonary vasodilators that reduce pulmonary vascular resistance, improving the performance of the RV and increasing cardiac output. Prostaglandin E1 is a member of the prostanoid family; it has been shown to improve pulmonary hemodynamics and the outcome of patients with $\mathrm{PH}$ that have undergone correction of congenital cardiac illnesses with an important decrease in mortality compared with conventional therapy [44]. In a series of 208 patients of cardiac transplant, PGE1 reverted increased pulmonary vascular resistance in the acute phase of the treatment [45].

Epoprostenol is available for inhaled or intravenous administration. Inhaled administration in a series of 20 patients reduced pulmonary pressure and improved systolic work of the $\mathrm{RV}$, a dose of $60 \mu \mathrm{g}$ is hemodynamically safe and its effect is reverted in $25 \mathrm{~min}$ [46]. Compared to nitric oxide, the administration is easy, does not require special equipment and is free of secondary toxic effects and the cost savings are substantial $[47,48]$.

In cardiac and pulmonary transplants, inhaled prostacyclin and nitric oxide reduce arterial pressure in a similar way, improving the $\mathrm{CI}$ and venous oxygen saturation, making prostacyclin an alternative in the treatment of $\mathrm{PH}$ in thoracic transplants [49].

Iloprost is a synthetic analog of PGI2; it is a potent pulmonary vasodilator without systemic effects, but with antiplatelet and antiproliferative effects. In a clinical trial with 46 patients it was more effective in reducing $\mathrm{PH}$ immediately after the removal of the CPB [50]. When administered in combination with nitric oxide it reduces pulmonary hypertension and contributes to the improvement of the RV function [40].

\section{Pulmonary vasodilation with PDE5 inhibitors}

These molecules reduce pulmonary vascular resistance by se- lectively and strongly inhibiting PDE5, but also reduce systemic resistance. Sildenafil improves cardiac output by balancing pulmonary and systemic vasodilation and also has a synergetic effect with nitric oxide [51].

In a series of 90 patients, sildenafil improved early diagnosis of patients with left side valve surgery, reduced days of mechanical ventilation and time in intensive care unit [52].

Gandhi et al showed in a clinical trial with 40 patients that suffered from severe $\mathrm{PH}$ that were scheduled for mitral valve replacement that sildenafil administered before surgery reduced $\mathrm{PH}$ and the need for mechanical ventilation compared to placebo [53].

Sildenafil has also been attributed with a potential role in the decrease of pulmonary vascular resistance and the incidence of acute RVF related to the LVAD implant [54].

\section{Contractibility optimization}

Inotropics support the free wall of the RV and together with the septum are another determinant of the global function of the RV. Dobutamine acts through the stimulation of the $\mathrm{B}_{1}$ receptor, a dose of $5-10 \mu \mathrm{g} / \mathrm{kg} / \mathrm{min}$ improves the coupling between the pulmonary artery and the RV, and it decreases pulmonary resistance and improves contractibility $[55,56]$. The drug may increase cardiac output with a lower risk of hypertension than levosimendan [57], and in coronary revascularization surgery, it has been linked to decreases in pulmonary microvascular pressure that may produce fewer pulmonary complications of the CPB [58]. In a series of 60 patients with mitral valve surgery, inotropic activity was higher than that of levosimendan [59], but the association improves systolic volume in patients that underwent $\mathrm{CPB}$ with a depressed ejection fraction [60].

Milrinone, similar to dobutamine, may restore blood flow in tissues and the substitution of oxygen in patients with low output due to cardiac surgery [61], it is effective in patients with a depressed ejection fraction that underwent myocardial revascularization without ECC [62] and facilitates the removal of the CPB in patients with mitral stenosis and severe $\mathrm{PH}$ [63]. Its use has been related to the survival of patients with RVF associated with an LVAD [64]. Other effects may include internal mammary arterial spam prevention, anti-inflammatory properties, and improved splanchnic perfusion [65].

Levosimendan is a sensitizing agent of troponin $\mathrm{C}$ to intracellular calcium; randomized studies in cardiac surgery compared to placebo had shown better hemodynamic safety profile, but there were no differences in organ dysfunction [66]. In a prospective study of 200 patients with cardiac valve surgery or combined with coronary revascularization, levosimendan was associated with a reduced incidence of cardiac failure, but a higher risk of arterial hypotension and required vasopressors without an improvement in mortality [67]; the perioperative administration in 64 patients during a clinical trial regarding placebo in mitral valve surgery and low ejection fraction improved renal function and decreased the need for renal replacement therapy [68].

Two meta-analyses concluded in favor of levosimendan in early mortality, less postoperative complications, and bet- 
ter outcomes in the intensive care unit when compared to placebo or other inotropics. Nonetheless, it is suggested to wait for more clinical trials and more conclusive evidence $[69,70]$.

\section{Vasopressors}

Norepinephrine acts primarily on the a1 receptor causing vasoconstriction, but it has a modest inotropic effect due to stimulation of the $b 1$ receptor [71]. This stimulation facilitates the coupling between the pulmonary artery and the RV [55]. Use of norepinephrine was associated with an increase in post-surgical cardiac output in a study of cardiac surgery patients, and the effect was measured by the basal cardiac function, volume recruitment, and change in venous tone. The authors propose that the response in cardiac output to norepinephrine may be predicted with VSV [72]. Vasopressin pairs with the V1 receptors in the cells of the vascular smooth muscle [71], low dosages $(0.01-0.03 \mathrm{U} / \mathrm{min})$ produce pulmonary vasodilation through the stimulation of the endothelial nitric oxide, but at higher doses, it potentiates the response of catecholamine and causes coronary and pulmonary vasoconstriction [73]. A recent study in humans compared the in vitro effect of various vasopressor agents of human radial and pulmonary arteries; the sympathomimetic agents had similar vasoconstriction potency in both arteries, while vasopressin even though it has a potent effect of the radial artery, did not have an effect on pulmonary vascular tone [74].

\section{Mechanical Circulatory Assistance}

Mechanical circulatory support therapy to the RV is an advanced therapy and must be considered in postoperative RVF when it is rebellious to pharmacological management. The intra-aortic balloon pump (IABP) may improve coronary perfusion and translate into improved global ventricular performance, but its benefit is very controversial for the RV. Boeken et al described 79 patients with predominantly right LOCS treated with IABP with a survival rate of $63 \%$ and a significant increase of the CI and TAM [75]. Extracorporeal membrane oxygenation (ECMO) has been used successfully in cases of RVF; there are reported cases with satisfactory outcomes in massive pulmonary embolism and perioperative pulmonary endarterectomy $[76,77]$. In RVF caused by LVAD, Noly and collaborators compared venous-arterial ECMO support to the RVAD in pulmonary arteries and veins; there were no differences in the extent of the support, neither in hospital stay or mortality, even though the rate of complications was higher with ECMO [78]. There is described experience with less invasive devices like the RV function to allow the removal of the device [79].

In a revision, Lang et al concluded that the RV support as a bridge therapy to transplant or recovery in patients with RFV after cardiac surgery was related to an improved hemodynamic stability, but its use must be carefully considered taking into account the individual characteristics of each patient due to multiple risks and high mortality [80].

\section{Conclusion}

Two cases of postoperative RVF were described, with ventilation, pharmacological, and similar medical support interventions, one of the cases with a successful outcome, another non-favorable. This shows a sample of the variable clinical complexity of right cardiac failure after surgery.

Refractory RVF has a low incidence but high morbidity and mortality in cardiac surgery. Understanding of the physiopathology has allowed the development of therapeutic strategies that are more effective. The key to this management consists in the preoperative identification of the patients at risk with RVF, the early recognition of the right dysfunction, and rapid treatment focused on decreasing pulmonary vascular resistance, optimizing the ventricular performance, and maintaining the contribution of the interventricular septum and the free wall of the RV, through the use of vasodilators, inotropics, and the delicate volume equilibrium state. Refractory right failure may be an indication of mechanical circulatory support, but only in specific cases. There is a deep need for more clinical trials in critical medical scenarios.

\section{References}

1. Denault AY, Chaput M, Couture P, Hebert Y, Haddad F, Tardif JC. Dynamic right ventricular outflow tract obstruction in cardiac surgery. J Thorac Cardiovasc Surg. 2006;132(1):43-49.

2. Pinzani A, de Gevigney G, Pinzani V, Ninet J, Milon H, Delahaye JP. [Pre- and postoperative right cardiac insufficiency in patients with mitral or mitral-aortic valve diseases]. Arch Mal Coeur Vaiss. 1993;86(1):27-34.

3. Reichert CL, Visser CA, van den Brink RB, Koolen JJ, van Wezel HB, Moulijn AC, Dunning AJ. Prognostic value of biventricular function in hypotensive patients after cardiac surgery as assessed by transesophageal echocardiography. J Cardiothorac Vasc Anesth. 1992;6(4):429432.

4. Voelkel NF, Quaife RA, Leinwand LA, Barst RJ, McGoon MD, Meldrum DR, Dupuis J, et al. Right ventricular function and failure: report of a National Heart, Lung, and Blood Institute working group on cellular and molecular mechanisms of right heart failure. Circulation. 2006;114(17):1883-1891.

5. Schuuring MJ, van Gulik EC, Koolbergen DR, Hazekamp MG, Lagrand WK, Backx AP, Mulder BJ, et al. Determinants of clinical right ventricular failure after congenital heart surgery in adults. J Cardiothorac Vasc Anesth. 2013;27(4):723-727.

6. Maslow AD, Regan MM, Panzica P, Heindel S, Mashikian J, Comunale ME. Precardiopulmonary bypass right ventricular function is associated with poor outcome after coronary artery bypass grafting in patients with severe left ventricular systolic dysfunction. Anesth Analg. 2002;95(6):1507-1518, table of contents.

7. Hosenpud JD, Bennett LE, Keck BM, Boucek MM, Novick RJ. The Registry of the International Society 
for Heart and Lung Transplantation: seventeenth official report-2000. J Heart Lung Transplant. 2000;19(10):909931.

8. Takeda K, Naka Y, Yang JA, Uriel N, Colombo PC, Jorde UP, Takayama H. Outcome of unplanned right ventricular assist device support for severe right heart failure after implantable left ventricular assist device insertion. J Heart Lung Transplant. 2014;33(2):141-148.

9. Ochiai Y, McCarthy PM, Smedira NG, Banbury MK, Navia JL, Feng J, Hsu AP, et al. Predictors of severe right ventricular failure after implantable left ventricular assist device insertion: analysis of 245 patients. Circulation. 2002;106(12 Suppl 1):I198-202.

10. Kormos RL, Gasior TA, Kawai A, Pham SM, Murali S, Hattler BG, et al. Transplant candidate's clinical status rather than right ventricular function defines need for univentricular versus biventricular support. J Thorac Cardiovasc Surg. 1996;111(4):773-82; discussion 82-83.

11. Ibrahim M, Hendry P, Masters R, Rubens F, Lam BK, Ruel M, Davies R, et al. Management of acute severe perioperative failure of cardiac allografts: a single-centre experience with a review of the literature. Can J Cardiol. 2007;23(5):363-367.

12. Haddad F, Couture P, Tousignant C, Denault AY. The right ventricle in cardiac surgery, a perioperative perspective: II. Pathophysiology, clinical importance, and management. Anesth Analg. 2009;108(2):422-433.

13. Itagaki S, Hosseinian L, Varghese R. Right ventricular failure after cardiac surgery: management strategies. Semin Thorac Cardiovasc Surg. 2012;24(3):188-194.

14. Haddad F, Doyle R, Murphy DJ, Hunt SA. Right ventricular function in cardiovascular disease, part II: pathophysiology, clinical importance, and management of right ventricular failure. Circulation. 2008;117(13):1717-1731.

15. Skhiri M, Hunt SA, Denault AY, Haddad F. [Evidencebased management of right heart failure: a systematic review of an empiric field]. Rev Esp Cardiol. 2010;63(4):451-471.

16. Green EM, Givertz MM. Management of acute right ventricular failure in the intensive care unit. Curr Heart Fail Rep. 2012;9(3):228-235.

17. Corres MA. Insuficiencia ventricular derecha en el seno de la cirugia cardiaca. Rev Esp Cardiol Supl. 2013;D(13):713.

18. Winterhalter M, Antoniou T, Loukanov T. Management of adult patients with perioperative pulmonary hypertension: technical aspects and therapeutic options. Cardiology. 2010;116(1):3-9.

19. Michaux I, Filipovic M, Skarvan K, Bolliger D, Schumann R, Bernet F, Seeberger MD. A randomized comparison of right ventricular function after on-pump versus off-pump coronary artery bypass graft surgery. J Thorac Cardiovasc Surg. 2011;141(2):361-367.

20. Ocal A, Kiris I, Erdinc M, Peker O, Yavuz T, Ibrisim E. Efficiency of prostacyclin in the treatment of protaminemediated right ventricular failure and acute pulmonary hypertension. Tohoku J Exp Med. 2005;207(1):51-58.

21. Denault A, Deschamps A, Tardif JC, Lambert J, Perrault L. Pulmonary hypertension in cardiac surgery. Curr Car- diol Rev. 2010;6(1):1-14.

22. Magne J, Mathieu P, Dumesnil JG, Tanne D, Dagenais F, Doyle D, Pibarot P. Impact of prosthesis-patient mismatch on survival after mitral valve replacement. Circulation. 2007;115(11):1417-1425.

23. Tscholl D, Langer F, Wendler O, Wilkens H, Georg T, Schafers HJ. Pulmonary thromboendarterectomy - risk factors for early survival and hemodynamic improvement. Eur J Cardiothorac Surg. 2001;19(6):771-776.

24. Klima U, Guerrero JL, Vlahakes GJ. Contribution of the interventricular septum to maximal right ventricular function. Eur J Cardiothorac Surg. 1998;14(3):250-255.

25. Klima UP, Lee MY, Guerrero JL, Laraia PJ, Levine RA, Vlahakes GJ. Determinants of maximal right ventricular function: role of septal shift. J Thorac Cardiovasc Surg. 2002;123(1):72-80

26. Kormos RL, Teuteberg JJ, Pagani FD, Russell SD, John $\mathrm{R}$, Miller LW, Massey T, et al. Right ventricular failure in patients with the HeartMate II continuous-flow left ventricular assist device: incidence, risk factors, and effect on outcomes. J Thorac Cardiovasc Surg. 2010;139(5):13161324.

27. Rudski LG, Lai WW, Afilalo J, Hua L, Handschumacher MD, Chandrasekaran K, Solomon SD, et al. Guidelines for the echocardiographic assessment of the right heart in adults: a report from the American Society of Echocardiography endorsed by the European Association of Echocardiography, a registered branch of the European Society of Cardiology, and the Canadian Society of Echocardiography. J Am Soc Echocardiogr. 2010;23(7):685-713; quiz 786-688.

28. Garcia Gigorro R, Renes Carreno E, Mayordomo S, Marin H, Perez Vela JL, Corres Peiretti MA, Montejo Gonzalez JC. Evaluation of right ventricular function after cardiac surgery: The importance of tricuspid annular plane systolic excursion and right ventricular ejection fraction. J Thorac Cardiovasc Surg. 2016;152(2):613-620.

29. Ventetuolo CE, Klinger JR. Management of acute right ventricular failure in the intensive care unit. Ann Am Thorac Soc. 2014;11(5):811-822.

30. Lee JH, No HJ, Song IK, Kim HS, Kim CS, Kim JT. Prediction of fluid responsiveness using a non-invasive cardiac output monitor in children undergoing cardiac surgery. Br J Anaesth. 2015;115(1):38-44.

31. Kuiper AN, Trof RJ, Groeneveld AB. Mixed venous O2 saturation and fluid responsiveness after cardiac or major vascular surgery. J Cardiothorac Surg. 2013;8:189.

32. Lee JH, Jeon Y, Bahk JH, Gil NS, Kim KB, Hong DM, Kim HJ. Pulse-pressure variation predicts fluid responsiveness during heart displacement for off-pump coronary artery bypass surgery. J Cardiothorac Vasc Anesth. 2011;25(6):1056-1062.

33. Fischer MO, Coucoravas J, Truong J, Zhu L, Gerard JL, Hanouz JL, Fellahi JL. Assessment of changes in cardiac index and fluid responsiveness: a comparison of Nexfin and transpulmonary thermodilution. Acta Anaesthesiol Scand. 2013;57(6):704-712.

34. Cannesson M, Slieker J, Desebbe O, Farhat F, Bastien $\mathrm{O}$, Lehot JJ. Prediction of fluid responsiveness using 
respiratory variations in left ventricular stroke area by transoesophageal echocardiographic automated border detection in mechanically ventilated patients. Crit Care. 2006;10(6):R171.

35. Belloni L, Pisano A, Natale A, Piccirillo MR, Piazza L, Ismeno G, De Martino G. Assessment of fluid-responsiveness parameters for off-pump coronary artery bypass surgery: a comparison among LiDCO, transesophageal echochardiography, and pulmonary artery catheter. J Cardiothorac Vasc Anesth. 2008;22(2):243-248.

36. Kholdani CA, Fares WH. Management of Right Heart Failure in the Intensive Care Unit. Clin Chest Med. 2015;36(3):511-520.

37. Mommerot A, Denault AY, Dupuis J, Carrier M, Perrault LP. Cardiopulmonary bypass is associated with altered vascular reactivity of isolated pulmonary artery in a porcine model: therapeutic potential of inhaled tezosentan. J Cardiothorac Vasc Anesth. 2014;28(3):698-708.

38. Solina AR, Ginsberg SH, Papp D, Grubb WR, Scholz PM, Pantin EJ, Cody RP, et al. Dose response to nitric oxide in adult cardiac surgery patients. J Clin Anesth. 2001;13(4):281-286.

39. Fernandes JL, Sampaio RO, Brandao CM, Accorsi TA, Cardoso LF, Spina GS, Tarasoutchi F, et al. Comparison of inhaled nitric oxide versus oxygen on hemodynamics in patients with mitral stenosis and severe pulmonary hypertension after mitral valve surgery. Am J Cardiol. 2011;107(7):1040-1045.

40. Antoniou T, Koletsis EN, Prokakis C, Rellia P, Thanopoulos A, Theodoraki K, Zarkalis D, et al. Hemodynamic effects of combination therapy with inhaled nitric oxide and iloprost in patients with pulmonary hypertension and right ventricular dysfunction after high-risk cardiac surgery. J Cardiothorac Vasc Anesth. 2013;27(3):459-466.

41. Matamis D, Pampori S, Papathanasiou A, Papakonstantinou P, Tsagourias M, Galiatsou E, Koulouras V, et al. Inhaled NO and sildenafil combination in cardiac surgery patients with out-of-proportion pulmonary hypertension: acute effects on postoperative gas exchange and hemodynamics. Circ Heart Fail. 2012;5(1):47-53.

42. Christenson J, Lavoie A, O'Connor M, Bhorade S, Pohlman A, Hall JB. The incidence and pathogenesis of cardiopulmonary deterioration after abrupt withdrawal of inhaled nitric oxide. Am J Respir Crit Care Med. 2000;161(5):1443-1449.

43. Namachivayam P, Theilen U, Butt WW, Cooper SM, Penny DJ, Shekerdemian LS. Sildenafil prevents rebound pulmonary hypertension after withdrawal of nitric oxide in children. Am J Respir Crit Care Med. 2006;174(9):10421047.

44. Dong MF, Ma ZS, Ma SJ, Chai SD, Tang PZ, Yao DK, Wang L. Effect of prostaglandin E1 on pulmonary arterial hypertension following corrective surgery for congenital heart disease. J Cardiovasc Pharmacol Ther. 2012;17(3):303-307.

45. von Scheidt W, Costard-Jaeckle A, Stempfle HU, Deng MC, Schwaab B, Haaff B, Naegele H, et al. Prostaglandin E1 testing in heart failure-associated pulmonary hypertension enables transplantation: the PROPHET study. J
Heart Lung Transplant. 2006;25(9):1070-1076.

46. Hache M, Denault A, Belisle S, Robitaille D, Couture P, Sheridan P, Pellerin M, et al. Inhaled epoprostenol (prostacyclin) and pulmonary hypertension before cardiac surgery. J Thorac Cardiovasc Surg. 2003;125(3):642-649.

47. De Wet CJ, Affleck DG, Jacobsohn E, Avidan MS, Tymkew H, Hill LL, Zanaboni PB, et al. Inhaled prostacyclin is safe, effective, and affordable in patients with pulmonary hypertension, right heart dysfunction, and refractory hypoxemia after cardiothoracic surgery. J Thorac Cardiovasc Surg. 2004;127(4):1058-1067.

48. Fattouch K, Sbraga F, Bianco G, Speziale G, Gucciardo M, Sampognaro R, Ruvolo G. Inhaled prostacyclin, nitric oxide, and nitroprusside in pulmonary hypertension after mitral valve replacement. J Card Surg. 2005;20(2):171176.

49. Khan TA, Schnickel G, Ross D, Bastani S, Laks H, Esmailian F, Marelli D, et al. A prospective, randomized, crossover pilot study of inhaled nitric oxide versus inhaled prostacyclin in heart transplant and lung transplant recipients. J Thorac Cardiovasc Surg. 2009;138(6):14171424.

50. Winterhalter M, Simon A, Fischer S, Rahe-Meyer N, Chamtzidou N, Hecker H, Zuk J, et al. Comparison of inhaled iloprost and nitric oxide in patients with pulmonary hypertension during weaning from cardiopulmonary bypass in cardiac surgery: a prospective randomized trial. J Cardiothorac Vasc Anesth. 2008;22(3):406-413.

51. Lepore JJ, Maroo A, Bigatello LM, Dec GW, Zapol WM, Bloch KD, Semigran MJ. Hemodynamic effects of sildenafil in patients with congestive heart failure and pulmonary hypertension: combined administration with inhaled nitric oxide. Chest. 2005;127(5):1647-1653.

52. Jiang G, Li B, Zhang G, Xu E, Liu Y, Xu Z. Effects of sildenafil on prognosis in patients with pulmonary hypertension after left-sided valvular surgery. Heart Lung Circ. 2014;23(7):680-685.

53. Gandhi H, Shah B, Patel R, Toshani R, Pujara J, Kothari J, Shastri N. Effect of preoperative oral sildenafil on severe pulmonary artery hypertension in patients undergoing mitral valve replacement. Indian J Pharmacol. 2014;46(3):281-285.

54. Hamdan R, Mansour H, Nassar P, Saab M. Prevention of right heart failure after left ventricular assist device implantation by phosphodiesterase 5 inhibitor. Artif Organs. 2014;38(11):963-967.

55. Kerbaul F, Rondelet B, Motte S, Fesler P, Hubloue I, Ewalenko P, Naeije R, et al. Effects of norepinephrine and dobutamine on pressure load-induced right ventricular failure. Crit Care Med. 2004;32(4):1035-1040.

56. Leier CV, Heban PT, Huss P, Bush CA, Lewis RP. Comparative systemic and regional hemodynamic effects of dopamine and dobutamine in patients with cardiomyopathic heart failure. Circulation. 1978;58(3 Pt 1):466475.

57. Alvarez J, Bouzada M, Fernandez AL, Caruezo V, Taboada M, Rodriguez J, Ginesta V, et al. [Hemodynamic effects of levosimendan compared with dobutamine in patients with low cardiac output after cardiac surgery]. 
Rev Esp Cardiol. 2006;59(4):338-345.

58. AH OY, Laub GW, Sanders SP, Dullye LJ, Reibman JB, McGrath LB. Reduction in pulmonary microvascular pressure following cardiopulmonary bypass: beneficial effects of dobutamine. Int Surg. 1995;80(3):231-234.

59. Gandham R, Syamasundar A, Ravulapalli H, Karthekeyan RB, Vakamudi M, Kodalli R, Nandipati S. A comparison of hemodynamic effects of levosimendan and dobutamine in patients undergoing mitral valve repair / replacement for severe mitral stenosis. Ann Card Anaesth. 2013;16(1):11-15.

60. De Hert SG, Lorsomradee S, Cromheecke S, Van der Linden PJ. The effects of levosimendan in cardiac surgery patients with poor left ventricular function. Anesth Analg. 2007;104(4):766-773.

61. Carmona MJ, Martins LM, Vane MF, Longo BA, Paredes LS, Malbouisson LM. Comparison of the effects of dobutamine and milrinone on hemodynamic parameters and oxygen supply in patients undergoing cardiac surgery with low cardiac output after anesthetic induction. Rev Bras Anestesiol. 2010;60(3):237-246.

62. Hadadzadeh M, Hosseini SH, Mostafavi Pour Manshadi SM, Naderi N, Emami Meybodi M. Effect of milrinone on short term outcome of patients with myocardial dysfunction undergoing off-pump coronary artery bypass graft: a randomized clinical trial. Acta Med Iran. 2013;51(10):681-686.

63. Oztekin I, Yazici S, Oztekin DS, Goksel O, Issever H, Canik S. Effects of low-dose milrinone on weaning from cardiopulmonary bypass and after in patients with mitral stenosis and pulmonary hypertension. Yakugaku Zasshi. 2007;127(2):375-383.

64. Tsiouris A, Paone G, Brewer RJ, Nemeh HW, Borgi J, Morgan JA. Outcomes of patients with right ventricular failure on milrinone after left ventricular assist device implantation. ASAIO J. 2015;61(2):133-138.

65. Levy JH, Bailey JM, Deeb GM. Intravenous milrinone in cardiac surgery. Ann Thorac Surg. 2002;73(1):325-330.

66. Erb J, Beutlhauser T, Feldheiser A, Schuster B, Treskatsch $\mathrm{S}$, Grubitzsch H, Spies C. Influence of levosimendan on organ dysfunction in patients with severely reduced left ventricular function undergoing cardiac surgery. J Int Med Res. 2014;42(3):750-764.

67. Lahtinen P, Pitkanen O, Polonen P, Turpeinen A, Kiviniemi V, Uusaro A. Levosimendan reduces heart failure after cardiac surgery: a prospective, randomized, placebocontrolled trial. Crit Care Med. 2011;39(10):2263-2270.

68. Baysal A, Yanartas M, Dogukan M, Gundogus N, Kocak T, Koksal C. Levosimendan improves renal outcome in cardiac surgery: a randomized trial. J Cardiothorac Vasc Anesth. 2014;28(3):586-594.
69. Lim JY, Deo SV, Rababa'h A, Altarabsheh SE, Cho YH, Hang D, McGraw M, et al. Levosimendan Reduces Mortality in Adults with Left Ventricular Dysfunction Undergoing Cardiac Surgery: A Systematic Review and Metaanalysis. J Card Surg. 2015;30(7):547-554.

70. Zhou C, Gong J, Chen D, Wang W, Liu M, Liu B. Levosimendan for Prevention of Acute Kidney Injury After Cardiac Surgery: A Meta-analysis of Randomized Controlled Trials. Am J Kidney Dis. 2016;67(3):408-416.

71. Hollenberg SM. Vasoactive drugs in circulatory shock. Am J Respir Crit Care Med. 2011;183(7):847-855.

72. Maas JJ, Pinsky MR, de Wilde RB, de Jonge E, Jansen JR. Cardiac output response to norepinephrine in postoperative cardiac surgery patients: interpretation with venous return and cardiac function curves. Crit Care Med. 2013;41(1):143-150.

73. Evora PR, Pearson PJ, Schaff HV. Arginine vasopressin induces endothelium-dependent vasodilatation of the pulmonary artery. V1-receptor-mediated production of nitric oxide. Chest. 1993;103(4):1241-1245.

74. Currigan DA, Hughes RJ, Wright CE, Angus JA, Soeding PF. Vasoconstrictor responses to vasopressor agents in human pulmonary and radial arteries: an in vitro study. Anesthesiology. 2014;121(5):930-936.

75. Boeken U, Feindt P, Litmathe J, Kurt M, Gams E. Intraaortic balloon pumping in patients with right ventricular insufficiency after cardiac surgery: parameters to predict failure of IABP Support. Thorac Cardiovasc Surg. 2009;57(6):324-328.

76. Deehring R, Kiss AB, Garrett A, Hillier AG. Extracorporeal membrane oxygenation as a bridge to surgical embolectomy in acute fulminant pulmonary embolism. Am J Emerg Med. 2006;24(7):879-880.

77. Berman M, Tsui S, Vuylsteke A, Snell A, Colah S, Latimer R, Hall R, et al. Successful extracorporeal membrane oxygenation support after pulmonary thromboendarterectomy. Ann Thorac Surg. 2008;86(4):1261-1267.

78. Noly PE, Kirsch M, Quessard A, Leger P, Pavie A, Amour J, Leprince P. Temporary right ventricular support following left ventricle assist device implantation: a comparison of two techniques. Interact Cardiovasc Thorac Surg. 2014;19(1):49-55.

79. Cheung AW, White CW, Davis MK, Freed DH. Shortterm mechanical circulatory support for recovery from acute right ventricular failure: clinical outcomes. J Heart Lung Transplant. 2014;33(8):794-799.

80. Lang SA, O'Neill B, Waterworth P, Bilal H. Can the temporary use of right ventricular assist devices bridge patients with acute right ventricular failure after cardiac surgery to recovery? Interact Cardiovasc Thorac Surg. 2014;18(4):499-510. 